\title{
Oficinas pedagógicas de enfrentamento ao trabalho infantil: memória, oralidade e expressão estética
}

Pedagogical workshops to coping child labor: memory, orality and aesthetic expression

\author{
Dimas Antônio de Souza ${ }^{a}$ \\ (D) http://orcid.org/0000-0002-1947-3604 \\ João Alves de Souza Junior ${ }^{a}$ \\ (D) http://orcid.org/0000-0003-4954-3711
}

\begin{abstract}
This article reports the experience in a training course about child labor, in which, through pedagogical workshops that involved the participants' memories, orality and aesthetic expressions, sought to denaturalize the phenomenon, giving it a new meaning, thus favoring their identification and coping. The course was offered to 333 Social Assistance technicians from 98 municipalities in Minas Gerais.
\end{abstract}

Keywords: Child labor. Pedagogical workshops. Memory. Orality. Aesthetic expression. 


\section{Introdução}

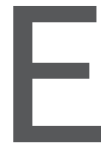

ntre os meses de setembro e novembro de 2017, assumimos a responsabilidade junto à Secretaria de Estado de Desenvolvimento Social de Minas Gerais (SEDESE/MG) de promover a capacitação aos profissionais da rede pública do Sistema Único de Assistência Social (SUAS), provenientes dos municípios com maior incidência de trabalho infantil no Estado, objetivando qualificar o enfrentamento do fenômeno. O curso presencial de 24 horas ocorreu em cinco cidades-polo, reunindo o total de 333 profissionais provenientes de 98 municípios mineiros.

O termo de referência que nos foi apresentado para a elaboração da capacitação exigia-nos que - para além da apresentação dos marcos conceituais e legais sobre o trabalho infantil, bem como das questões específicas do Programa de Erradicação do Trabalho Infantil (PETI) no contexto do SUAS - propiciássemos aos cursistas a compreensão sobre os elementos históricos e culturais que envolvem o trabalho infantil, visando a sua desnaturalização e, ao mesmo tempo, a sua ressignificação, sensibilizando os participantes quanto à gravidade do problema. Também exigia o desenvolvimento de novas linguagens para a abordagem e intervenção social.

Por opção teórica, resolvemos explorar a história de vida dos participantes de modo a constituirmos uma memória, individual e coletiva, acerca do trabalho infantil. Essa memória, permeada inicialmente de saudosismos românticos, uma vez revisitada a partir do conceito de trabalho infantil, permitiu que os participantes identificassem e percebessem na sua própria história de vida, ou em seu entorno, a presença e os efeitos individuais e sociais do trabalho infantil, propiciando-lhes uma ressignificação do fenômeno.

O presente relato de experiência apresenta uma reflexão acerca da necessidade de enfrentarmos o trabalho infantil como um fator cultural, e relata como, a partir de oficinas criativas e lúdicas, nas quais recuperamos a memória dos participantes e possibilitamos que eles a expressassem 
pela oralidade, pelo desenho e pelo próprio corpo, em linguagem teatral, permitiu aos cursistas um novo olhar acerca do tema e, ao mesmo tempo, acabou por se conformar como instrumento de linguagem simples e potente para a abordagem e intervenção social.

\section{Enfrentando o trabalho infantil como um fator cultural}

Segundo a Organização Internacional do Trabalho (OIT), o "trabalho infantil é aquele realizado por crianças e adolescentes que estão abaixo da idade mínima para a entrada no mercado de trabalho, segundo a legislação em vigor no país" (OIT, 2001). No Brasil, a Constituição Federal de 1988 e o Estatuto da Criança e do Adolescente (ECA) definem como trabalho infantil toda atividade laboral, remunerada ou não, de menores de 14 anos. Acima dos 14 anos é permitido o trabalho sob o regime da aprendizagem e, aos que possuem 16 anos e menos que 18, o trabalho é permitido, desde que respeitadas as condições estabelecidas pela lei, que o proíbe em casos de trabalho perigoso, insalubre, penoso, noturno ou que coloque em risco o desenvolvimento físico, psíquico, moral e social do adolescente.

Não obstante a lei seja clara a respeito, o trabalho infantil tem se manifestado um fenômeno resiliente, uma vez que há elementos de ordem cultural que favorecem a sua continuidade. A cultura, explica-nos a clássica antropóloga Ruth Benedict (2000), é a lente através da qual enxergamos, ou melhor, compreendemos o mundo. Com efeito, embora nossos órgãos de sentido captem imagens, odores, sabores, sons e reconheçam superfícies, esses, para serem interpretados, carecem da informação cultural, ou seja, necessitam basicamente da linguagem.

É por meio da linguagem que aprendemos o nome das coisas, das cores, que reconhecemos os ruídos, que distinguimos os odores e os sabores, que aprendemos os valores morais da sociedade, que absorvemos suas concepções religiosas, suas ideologias, suas crenças, enfim, a linguagem nos introduz a um conjunto articulado de conceitos, concatenados e que 
fazem sentido entre si, e é por meio deles que nós compreendemos o mundo e nele agimos.

Muitos desses conceitos, formados há tempos imemoriais e repassados de geração em geração, carregam consigo conteúdos nem sempre condizentes com os modernos conceitos científicos e mesmo com a legislação em vigor no país. Tais noções, por serem valores culturais, sobrevivem e, pior, continuam a ser ensinados, como é o caso do trabalho infantil. Soam familiares as frases: "O trabalho dignifica e enobrece o homem"; "Mente vazia oficina do diabo"; "Trabalhar não faz mal”; "É melhor trabalhar do que ficar na rua à toa”; ou, ainda, "É melhor vender pão de queijo do que traficar drogas".

Sendo a valorização do trabalho infantil no Brasil um dado cultural e o seu enfrentamento na forma de lei relativamente recente, e ainda, a constatação de que muitos dos que hoje são adultos passaram pela experiência do trabalho infantil, isso faz com que a prática seja tão comum entre nós que a naturalizamos, ou seja, a transformamos em um comportamento normal, corriqueiro, ao ponto de passarmos pelo trabalho infantil pelas ruas e vê-lo, sem, no entanto, percebê-lo. Essa naturalização do trabalho infantil provoca a invisibilidade do fenômeno, o que dificulta em muito o enfrentamento do problema, uma vez que o próprio agente do sistema de proteção está imerso nessa complexa teia de valores.

Partindo dessa compreensão exposta, foram elaboradas oficinas de modo a permitir que, de forma sensível, criativa e lúdica, em construção coletiva e horizontal, por meio de atividades básicas que perpassaram o campo da memória, da oralidade e da expressão artística, criássemos momentos nos quais os profissionais das redes municipais de Assistência Social, ao se apropriarem do conceito de trabalho infantil, pudessem ressignificá-lo em sua própria história de vida. As oficinas também foram elaboradas levando em consideração a simplicidade dos recursos necessários para que fossem realizadas, de modo que pudessem ser facilmente replicadas nos territórios junto ao público-alvo do Programa de Erradicação do Trabalho Infantil. 


\section{A oficina pedagógica como fator de mudança de paradigma}

De acordo com Paulo Freire (2003), ensinar não é ato de transferir conhecimentos, mas de criar as possibilidades para que os sujeitos envolvidos no processo possam participar de sua construção, ou seja, possam produzir o conhecimento. Nesse sentido, as oficinas pedagógicas abrem espaços para participação, aprendizagem e sistematização dos saberes em pauta, constituindo-se como lugar de interação e troca, por meio de dinâmicas, atividades coletivas e individuais, de modo a permitirem que se religuem a teoria com prática e a educação com a vida.

De acordo com Candau et al. (1995), a oficina pedagógica possibilita a construção de um espaço de elaboração coletiva dos saberes, dado que incentiva a troca de experiências, a observância de situações concretas, o confronto de ideias e a análise da realidade, de uma forma crítica e horizontal, uma vez que a palavra é franqueada e o educando assume o protagonismo. Nessa mesma orientação, Graciani (1997) afirma que o processo educativo que nas oficinas se realiza envolve a sensibilização, a compreensão, a reflexão, a análise, a ação e a avaliação. Dessa maneira, do conhecimento assim construído, de forma criativa, crítica e participativa, espera-se que não se limite apenas a compreender, mas fundamentalmente a transformar a realidade.

Desse modo, objetivando que os profissionais da rede socioassistencial percebessem como o fator cultural opera em sua própria prática e seguindo o escopo teórico apresentado nas aulas de abertura, as quais dedicamos a esclarecer os aspectos relevantes dos elementos culturais que tornam invisível e que naturalizam o trabalho infantil, bem como a definir o marco conceitual e legal do trabalho infantil no Brasil, convidamos os cursistas a uma introspecção em suas memórias por meio de três oficinas.

A primeira, intitulada "Dinâmica do relógio: memória e oralidade"; a segunda, "Desenho, sensibilização, memória e oralidade"; a terceira, 
buscando reproduzir nos próprios corpos que rememoraram coletivamente as cenas que, direta ou indiretamente, foram por eles vividas e expressas pelos desenhos da oficina anterior, utilizamos a técnica do “Teatro imagem”, de Augusto Boal.

\section{Dinâmica do relógio: ${ }^{1}$ memória e oralidade}

Os participantes receberam uma folha de papel A3 com um relógio impresso, o qual eles deveriam preencher, indicando os horários e as atividades que realizavam cotidianamente quando possuíam entre 10 e 14 anos de idade. Todos demonstraram um alto interesse e disponibilidade ao desenvolver a atividade, o que proporcionou uma excelente interatividade, envolvimento e produção durante a oficina. O mesmo ocorreu quando foram chamados a apresentar oralmente os seus respectivos relógios, momento em que a carga emocional foi ainda maior e que desencadeou lágrimas e sorrisos.

Dentre os 333 participantes do curso, 77 ou 23,1\% identificaram o trabalho infantil em sua história de vida, sendo que, em alguns casos, foi observado mais de um tipo por pessoa. Na Figura 1, mostramos os tipos de trabalho infantil que foram identificados entre os cursistas por meio da Dinâmica do relógio.

Essas oficinas tiveram como fio condutor a exploração da memória individual, considerando que esta, como afirma Le Ven (2008), embora seja individual, não é exatamente uma construção solitária, uma vez que se faz conjuntamente com a complexa rede das relações sociais passadas e presentes. Sendo que a memória é condição sine qua non para darmos sentido à vida, é nela que buscamos respostas para os nossos atos presentes, e, somente através de uma revisita à memória, podemos encontrar elementos para atribuirmos novos sentidos à vida.

A origem dessa dinâmica: Escola Sindical 7 de Outubro. Belo Horizonte/MG. Adaptada para o tema do trabalho infantil. 
Figura 1. Tipos de trabalho infantil - Oficina $n^{\circ} 1$ - Minas Gerais.

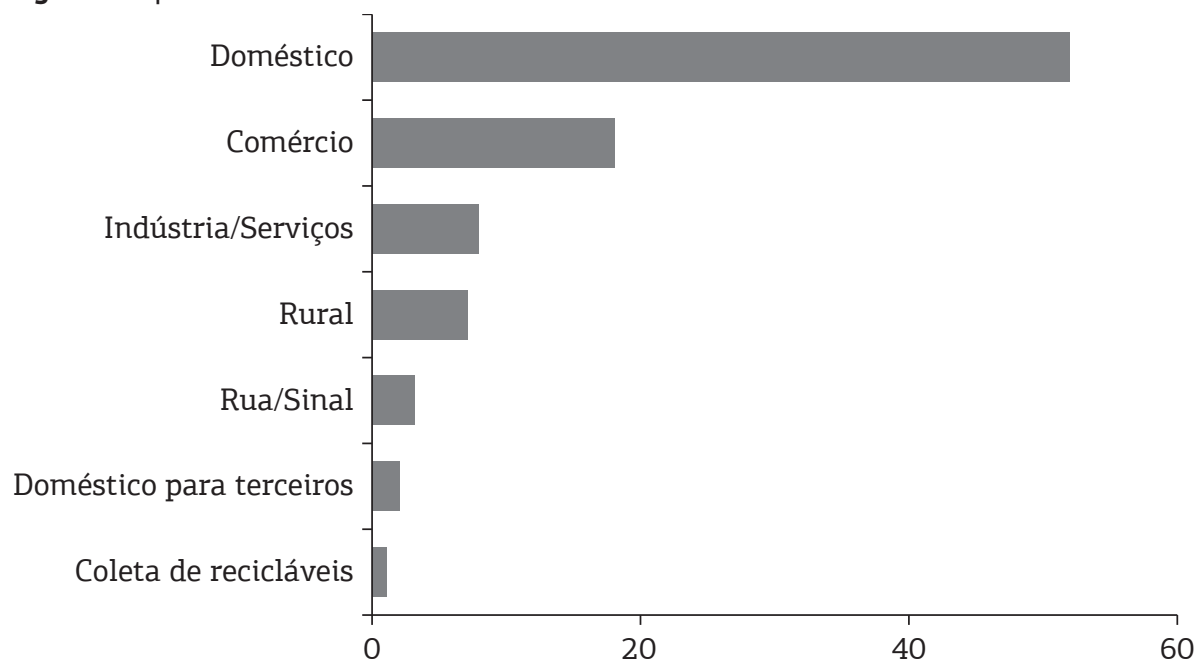

Fonte: elaborada pelos autores, 2017.

Assim, ao revolvermos a memória, torna-se possível desenvolver um processo pedagógico que parte da história de vida dos sujeitos, portanto, de sua própria experiência. A psicanálise toma a questão da memória considerando-a um processo não linear, mas como camadas, formadas a partir das experiências vividas, que vão se reordenando, de modo a remodelar-se. Não pode ser comparada a um baú, onde são depositados acontecimentos, mas, para além disso, um mesmo registro pode passar por diferentes leituras pela memória, à medida que são vivenciadas novas experiências por parte do sujeito.

Na Carta 52 ao amigo Fliess, Freud menciona esse caráter plástico da memória:

[...] tu sabes que trabalho com a hipótese de que nosso mecanismo psíquico se gerou por uma estratificação sucessiva, pois de tempo em tempo o material preexistente de marcas mnêmicas experimenta uma reordenação segundo novos nexos, uma retranscrição. $O$ essencialmente novo em minha teoria é, então, a tese de que a memória não preexiste de maneira 
simples, senão múltipla, está registrada em diversas variedades de signos (Freud, 1976, p. 274).

Nesse sentido, a utilização da memória como uma linha condutora das atividades se apoia na sua própria plasticidade e, por isso, na possibilidade de ressignificação de experiências. Bosi (2003) nos diz que, pela memória, o passado não só vem à tona, ao presente, mas também, misturando-se com as percepções imediatas, descola destas últimas, ocupando o espaço todo da consciência. A memória aparece como força subjetiva, ao mesmo tempo profunda e ativa, latente e penetrante, oculta e invasora.

Outro suporte importante dessas oficinas, que caminha com a memória, é a oralidade. Em consonância com pressupostos da psicanálise, entendemos que o narrar sobre si, sobre a sua própria história de vida, permite que os indivíduos se reposicionem em relação à sua própria práxis. "A oralidade e o cuidado de si e dos outros, próprios dessa prática, têm efeitos (e afetos) nos indivíduos" (Le Ven, 2008, p. 52). No que se refere à oralidade, consideramos que os fundamentos da psicanálise nos apontam uma função catártica e ressignificadora da oralidade, operando o discurso no campo da transformação.

Segundo Waleska Pessato Fochesatto (2018), por meio da fala é dada ao sujeito a oportunidade de acessar ideias recalcadas, passando a ter uma nova compreensão de si, de suas memórias. Supõe-se que, na medida em que o sujeito mantém ideias recalcadas de eventos ligados ao passado, este se torna presente por meio da fala, no caso específico, interessava-nos que os participantes pudessem refletir sobre suas experiências com o trabalho infantil e que essa reflexão repercutisse em sua atuação profissional presente. Nesse sentido, a Dinâmica do relógio cumpriu o seu papel inicial, abrindo os caminhos para a oficina seguinte, na qual associamos o exercício da memória à expressividade estética. 
Desenho, sensibilização, memória e oralidade

Foram fornecidos aos participantes papéis e canetas coloridas e solicitou-se que eles representassem em desenhos os tipos de trabalho infantil que eram realizados em seu meio, na época de sua infância e adolescência. Concluídos os cartazes, os cursistas foram convidados a expor o seu trabalho para o grupo. Por seu turno, o coletivo foi desafiado a identificar nos desenhos os tipos de trabalho infantil que foram representados.

Figura 2. Tipos de trabalho infantil representados nos desenhos - Oficina $n^{\circ} 2$ - Minas Gerais.

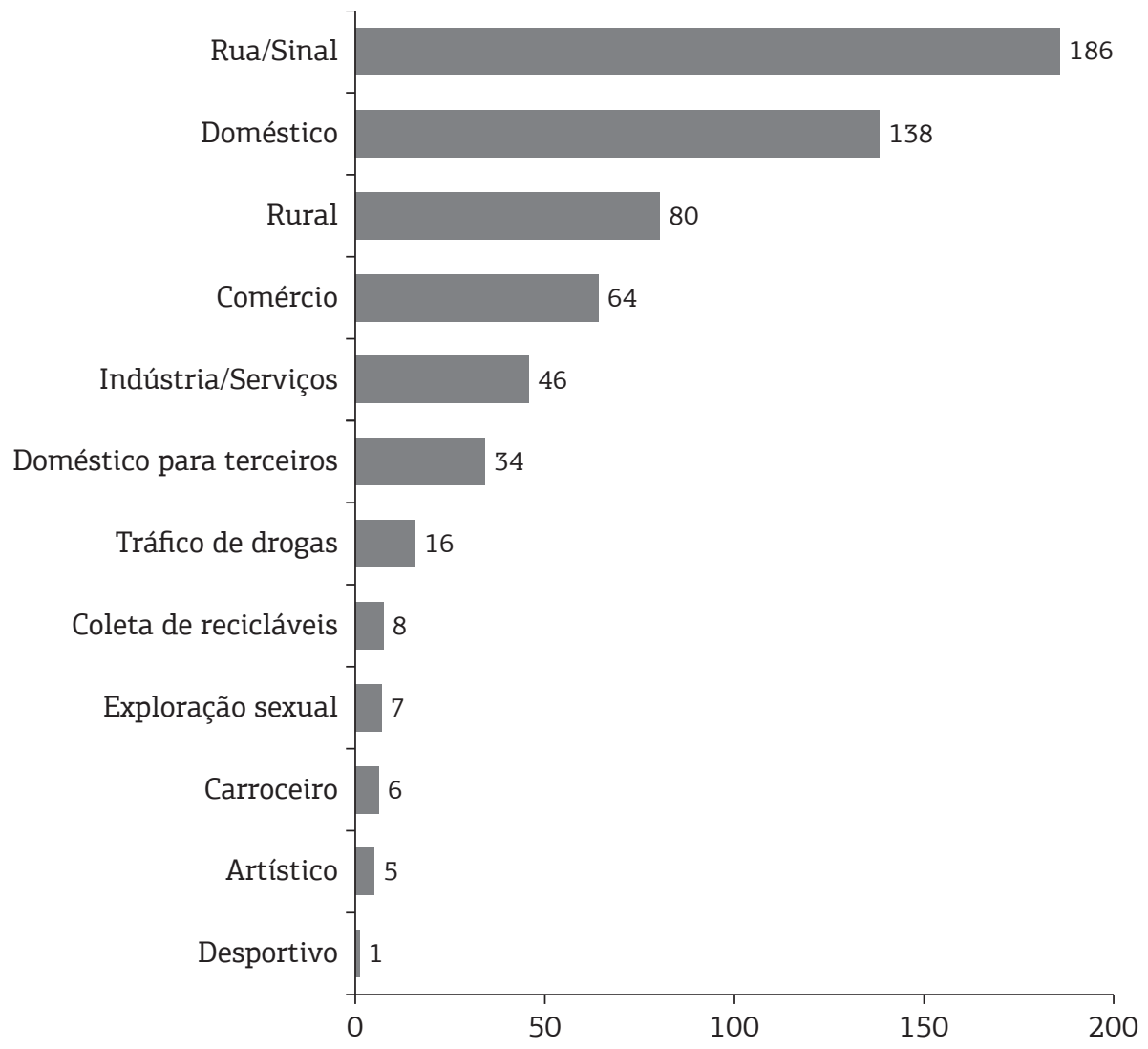

Fonte: elaborada pelos autores, 2017. 
O desenho esboça possibilidades para expandir o tempo, o espaço, as emoções, os sabores e os saberes simbolizados através das projeções das imagens e, assim, nos leva a novas descobertas. Segundo Lagôa (2006), o traço torna-se responsável por um mundo de relações orgânicas, cada imagem adquire vida própria e força entre as demais.

Figura 3. Trabalho infantil.

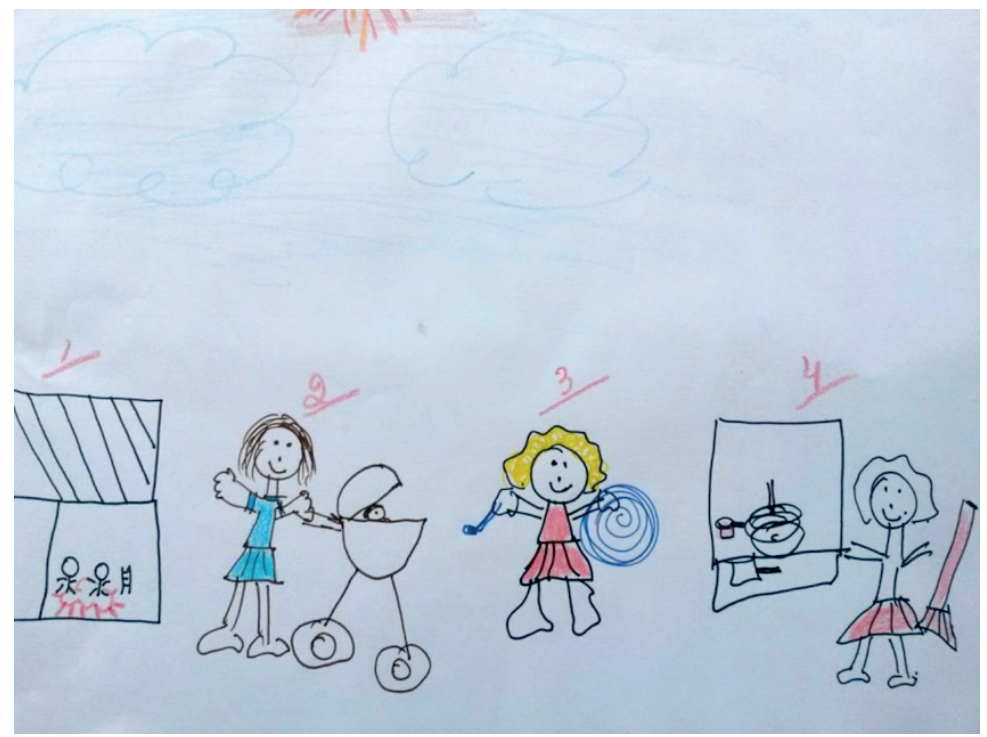

Fonte: alunos da Oficina 2 - Curso de capacitação sobre o trabalho infantil em parceria com a Secretaria Estadual de Desenvolvimento Social de Minas Gerais. Oficina 2 - Desenho, sensibilização e oralidade, 2017.

Tanto na criação quanto na observação, o ponto em movimento se transforma em linha, a linha em plano e o plano em espaço. A forma em construção nasce da linha, é constituída no caminho dela mesma, uma vez que sua dinâmica parte de um ponto fixo, transformado em agente de movimento. Segundo Lagôa (2006), pontos afins entre os trabalhos de Kandinsky e Klee corroboram o discurso da força ou estímulo psicológico presentes no ato de desenhar. Cabe salientar a importância de pensamentos e reverberações expressos por imagens. 
Figura 4. Trabalho infantil.

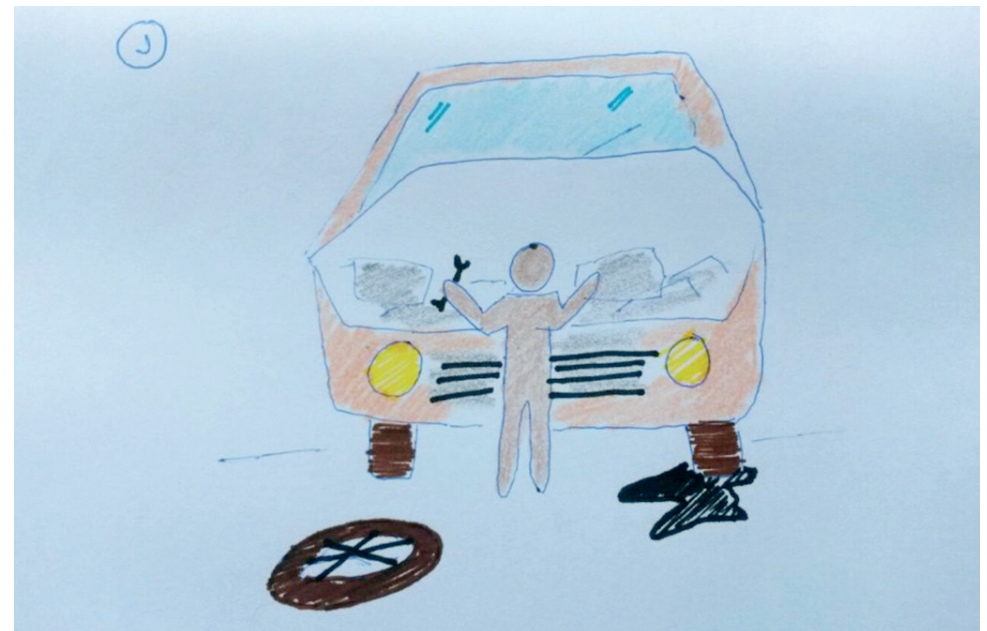

Fonte: alunos da Oficina 2 - Curso de capacitação sobre o trabalho infantil em parceria com a Secretaria Estadual de Desenvolvimento Social de Minas Gerais. Oficina 2 - Desenho, sensibilização e oralidade, 2017.

\section{Teatro imagem}

Seguindo a perspectiva do reconhecimento e a valorização da memória, da oralidade, da troca de experiências e da construção coletiva de conhecimentos a partir da realidade dos envolvidos, buscamos, na Oficina 3, por meio da utilização da linguagem teatral, possibilitar alternativas de comunicação que permitissem o aflorar da subjetividade de maneira mais profunda e, assim, a criação de oportunidades mais consistentes de ressignificação de conceitos e impressões.

Dentre as técnicas teatrais sugeridas por Boal, encontra-se o Teatro de imagem, em que os participantes foram convidados a, em grupo, representarem em cena um ou mais tipos de trabalho infantil que foram representados em desenho na Oficina 2.

Segundo Boal (1193, p. 5):

[...] a chamada Imagem de Transição tem por objetivo ajudar os participantes a pensar com imagens, a expor um problema sem o uso da palavra, 
usando apenas seus próprios corpos (posições corporais, expressões fisionômicas, distâncias e proximidades, etc.) e objetos.

Tendo em mãos os tipos de trabalho infantil representados em desenhos na Oficina 2 anterior, foi solicitado aos grupos que escolhessem um deles para, em forma de uma cena teatral fixa, por meio de posturas, expressões corporais, faciais, entre outros recursos corporais, sem uso da fala, representarem as formas de trabalho infantil escolhidas. A cena, após composta, movimenta-se por cinco segundos e se fixa novamente. Os observadores deviam identificar os tipos de trabalho infantil representados.

Figura 5. Cenas de trabalho infantil — SEDESE — Minas Gerais.

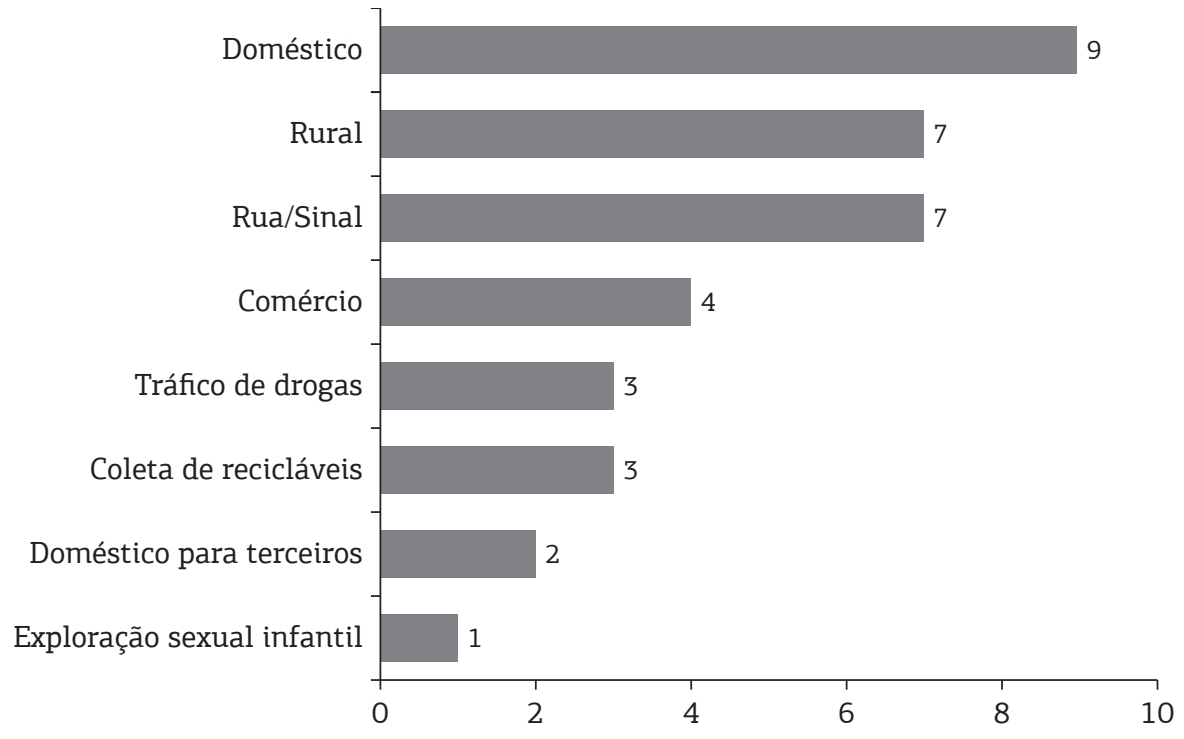

Fonte: elaborada pelos autores, 2017.

De acordo com Boal (1993, p. 228):

Se bato na minha mão agora, sinto a dor agora mesmo; se lembro de ter-me machucado ontem, posso provocar em mim hoje uma sensação 
análoga. Não é a mesma dor, mas memória dessa dor. Essa série nos ajuda a relacionar a memória à emoção e à imaginação, tanto no momento de preparar uma cena para o teatro, como quando estivermos preparando uma ação futura na realidade.

Mesmo diante das reclamações quanto à dificuldade do exercício, os grupos conseguiram elaborar as cenas com expressões corporais, faciais, explorando bem posicionamento e distâncias, e escolhendo um conteúdo bem contextualizado. Quanto à decodificação das cenas, importante para a identificação do trabalho infantil na prática profissional, em grande parte dos casos houve necessidade de que os grupos as explicassem aos demais participantes. O que já era esperado, uma vez que não estavam disponíveis ferramentas ou utensílios que pudessem ser facilmente relacionados ao ofício representado.

Figura 6. Trabalho infantil.

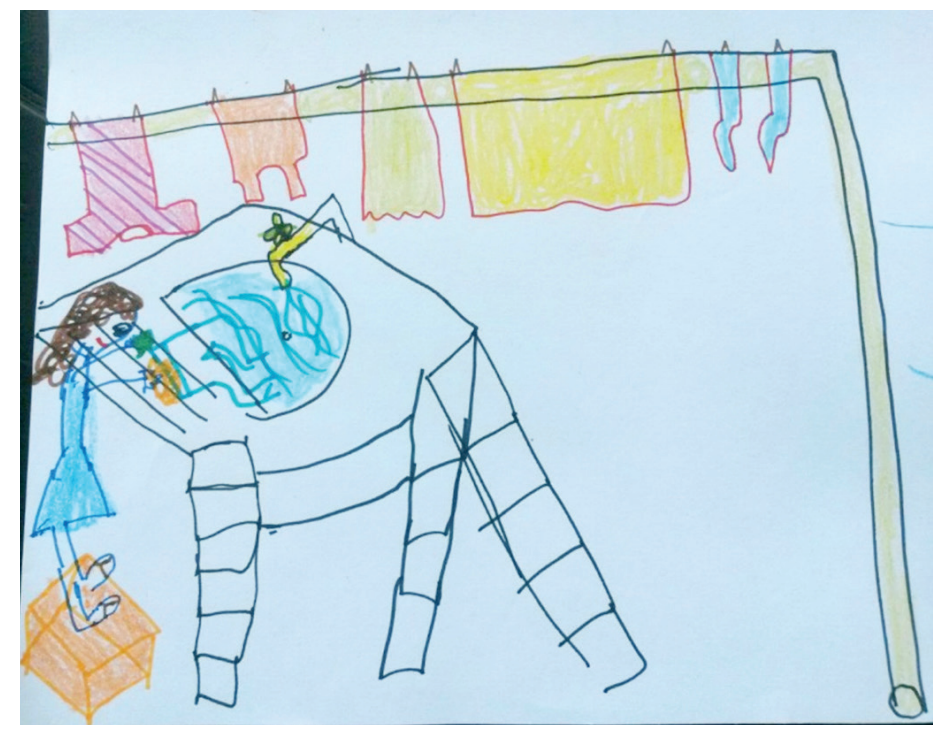

Fonte: alunos da Oficina 2 - Curso de capacitação sobre o trabalho infantil em parceria com a Secretaria Estadual de Desenvolvimento Social de Minas Gerais. Oficina 2 - Desenho, sensibilização e oralidade, 2017. 


\section{Considerações finais}

Durante os debates, alguns participantes se surpreenderam ao descobrir terem sido vítimas do trabalho infantil, chegando a estabelecer uma relação entre esse fato e algumas dificuldades que possuíam na atualidade, tais como, desempenho nos estudos, a forma de se relacionar, a autoestima e o nível de exigência consigo mesmo, além de outros desafios pessoais.

Foi também aprofundada a reflexão sobre os danos causados pelo trabalho infantil e alguns participantes relataram suas experiências referentes a esses danos, como dificuldades com os estudos no seu percurso escolar, inclusive na atualidade, referências à autoestima e a transtornos emocionais. Alguns, inclusive, relataram investir em tratamento psicológico, a fim de superar essas dificuldades desencadeadas pelas marcas deixadas por essas vivências. "Na faculdade, tenho que correr mais atrás do que meus colegas para dar conta dos estudos. Trabalho infantil traz consequências sim. Algumas reparáveis, outras não", foi o depoimento de uma das participantes.

Em contraponto, alguns técnicos afirmaram ter trabalhado na infância, não vendo isso como um fato negativo em suas vidas. Alguns chegaram a declarar que fora positivo, elencando algumas de suas características atuais, como responsabilidade, independência e outras, que teriam sido adquiridas em virtude de seu envolvimento com a atividade laboral precoce.

Também em alguns desenhos e cenas elaborados pelos participantes, o trabalho infantil foi retratado com crianças sorridentes. Nos comentários, discutiu-se sobre o fato de que o trabalho infantil pode ser percebido como uma atividade prazerosa pelos adolescentes. Alguns relataram ainda que, não raras vezes, entrevistaram adolescentes que afirmam gostar de trabalhar, que se sentem bem, aceitos, queridos e valorizados pela família e pela comunidade. 
A partir dessas análises, o binômio "melhor trabalhar do que roubar ou usar drogas" foi questionado por muitos participantes. As discussões favoreceram o consenso quanto à existência de muitas outras possibilidades entre esses dois extremos, inclusive as mais apropriadas, que se referem a estudos, lazer, atividades esportivas e culturais.

No caso, o fato de alguns deles terem, em certa medida, defendido o trabalho infantil como benéfico foi muito relevante, uma vez que o fato de o técnico não estar devidamente consciente e sensibilizado quanto ao drama do trabalho infantil pode facilitar a invisibilização do fenômeno, impedindo ou dificultando sua marcação pelos técnicos da Assistência e membros dos conselhos tutelares.

Depois do desenvolvimento das discussões e do reposicionamento de alguns participantes que haviam buscado justificar o trabalho infantil, eles observaram e perceberam como a cultura de naturalização do trabalho infantil se impõe sobre as nossas representações sobre o fenômeno e o quanto tal fenômeno pode interferir na atividade dos profissionais que atuam no seu enfrentamento.

Sabe-se que o trabalho infantil é um fenômeno que se reproduz nas famílias. Em geral, pais que trabalharam na infância estimulam seus filhos a trabalharem. $O$ trabalho infantil doméstico foi colocado pelos participantes como um dos maiores desafios do PETI, sendo que, por acontecer em ambiente privado, é muito difícil de ser identificado. Nesse sentido, destacou-se a importância da parceria com a educação e a saúde do fortalecimento das articulações em rede.

Nesse sentido, a grande conquista das oficinas foi, por meio de instrumentos simples e lúdicos, ter dado voz aos participantes que, a partir de suas histórias de vida, puderam refletir sobre o trabalho infantil. Entretanto, tal reflexão deixou de ser uma apreensão racional do tema, à medida que provocou a sensibilidade estética dos participantes, incluindo-os por inteiro, propiciando que eles incorporassem por alguns instantes, em cena, o próprio tema estudado. 
Como indicamos inicialmente, um dos propósitos das oficinas era o de instrumentalizar os técnicos com novas linguagens de intervenção e de diagnóstico social do fenômeno. Nesse sentido, as oficinas que realizamos se mostraram muito pertinentes. Realizadas com material de fácil acesso e de custo baixo, podem ser replicadas em qualquer lugar e com a grande maioria do público. E, por sua versatilidade, podem ser utilizadas em outras questões pertinentes à Assistência Social.

\section{Referências}

BENEDICT, Ruth. Padrões da cultura. Lisboa: Livros do Brasil, 2000.

BOAL, Augusto. Jogos para atores e não-atores. Rio de Janeiro: Civilização Brasileira, 1993. BOSI, Ecléa. O tempo vivo da memória: ensaios de psicologia social. São Paulo: Ateliê Editorial, 2003.

CANDAU, Vera Maria et al. Oficinas pedagógicas de direitos humanos. 2. ed. Petrópolis: Vozes, 1995.

FOCHESATTO, Waleska P. F. A cura pela fala. Estudos de Psicanálise, Belo Horizonte, n. 36, 2018. Disponível em: http://pepsic.bvsalud.org/scielo.php?script=sci arttext\&pid=S0100-34372011000300016. Acesso em: 25/11/2020.

FREIRE, Paulo. Pedagogia da autonomia: saberes necessários à prática educativa. 28. ed. São Paulo: Paz e Terra, 2003.

FREUD, Sigmund. Carta 52: fragmentos de la correspondencia con Fliess. In: FREUD, Sigmund. Obras completas. Buenos Aires: Amorrortu, 1976. v. 1, p. 274-280.

GRACIANI, Maria Stela S. Pedagogia social de rua. São Paulo: Cortez, 1997.

LAGÔA, Maria Beatriz R. O avesso do visível — poética de Paul Klee. Alea, Rio de Janeiro, v. 8, n. 1, 2006. Disponível em: https://www.scielo.br/scielo.php?pid=S1517106X2006000100009\&script=sci_arttext\&tlng=pt. Acesso em: 25/11/2020.

LE VEN, Michel Marie. Afeto e política: metodologia qualitativa: história oral de vida e sociologia clínica. Belo Horizonte: Faculdade de Letras da UFMG, 2008.

ORGANIZAÇÃO INTERNACIONAL DO TRABALHO. Combatendo o trabalho infantil: guia para educadores/IPEC. Brasília: OIT, 2001. 


\section{Sobre os autores}

Dimas Antônio de Souza - Doutor em Estudos Interdisciplinares sobre o Lazer. Professor convidado do Programa de Pós-Graduação em Direito. Professor do Instituto de Ciências Sociais. Contramestre de Capoeira Angola. Coordenador do Complexus: Instituto de Educação e Pesquisa Social.

E-mail:dimas@icomplexus.com.br

JoÃo Alves de Souza Junior - Doutorando e Mestre em Direitos Humanos, Integração e Estado Plurinacional pela PUC/MG. Bolsista Capes.

E-mail: joaoalvesmptmg@gmail.com 